\title{
Clinical Efficacy Analysis and Long-Term Follow-Up Outcomes of Robotic Versus Laparoscopic Sphincter-Preserving Surgery in Total Mesorectal Excision for Low Rectal Cancer: A Retrospective Cohort Study
}

\section{Bo Yang}

First Affiliated Hospital of Anhui Medical University department of general of surgery

\section{Shangxin Zhang}

First Affiliated Hospital of Anhui Medical University department of general of surgery

Xiaodong Yang

First Affiliated Hospital of Anhui Medical University department of general of surgery

\section{Yigao wang}

First Affiliated Hospital of Anhui Medical University department of general of surgery

\section{Deguan Li}

First Affiliated Hospital of Anhui Medical University department of general of surgery

\section{Jian Zhao}

First Affiliated Hospital of Anhui Medical University department of general of surgery

Yongxiang Li ( $\square$ liyongxiang@ahmu.edu.cn)

First Affiliated Hospital of Anhui Medical University department of general of surgery

\section{Research Article}

Keywords: Robotic surgery, Sphincter-preserving surgery, Total mesorectal excision, Low rectal cancer

Posted Date: November 30th, 2021

DOI: https://doi.org/10.21203/rs.3.rs-1070445/v1

License: () (i) This work is licensed under a Creative Commons Attribution 4.0 International License. Read Full License 


\section{Abstract}

Objective: The aim of this study is to compare short-term clinical efficacy and long-term follow-up outcomes of robotic-assisted sphincter-preserving surgery (RAS) with laparoscopic-assisted sphincter-preserving surgery (LAS) for low rectal cancer.

Method: This was a single-center retrospective cohort study of consecutive patients diagnosed with low rectal cancer who underwent laparoscopic or robotic sphincter-preserving surgery (RAS 200, LAS 486) between January 1, 2015 and July 1, 2018.

Results: Mean operation time was $249 \pm 64 \mathrm{~min}$ for RAS group and $249 \pm 64 \mathrm{~min}$ for LAS group (Pख0.001). the rate of temporary ileostomy was $64.5 \%$ for RAS and $51.6 \%$ for LAS ( $P=0.002$ ). Time to liquid diet, firstly leaving bed time, removing catheter time and length of stay showed significant difference (all P®0.001). The distance of distal resection margin in RAS group was closer than LAS group $(P=0.004)$. The recovery from decreased urinary and female sexual function took more than 6 months after surgery in LAS group (Pख0.0001) but 3 months in RAS group (Pख0.0001). Male sexual function 6 months postoperatively was better in RAS group than LAS group (P凶0.001). The Wexner score showed similar results at 6 months after surgery (Pख0.001). And no significantly group difference were observed for OS or DFS at 3 and 5 years after surgery.

Conclusion: Both robotic and laparoscopic sphincter-preserving surgery for low rectal cancer are safe and effective in clinical efficacy and long-term outcomes. The robotic approach showed some advantages in short-term recovery of urogenital and anorectal function.

\section{Introduction}

Rectal cancer is one of the most common cancer in digestive tract. And in terms of epidemiological studies, it has the trend of rejuvenation in the distributed population [1-3].

Radical resection is the optimal treatment for rectal cancer. Since the concept of minimally invasive surgery was proposed [4,5], laparoscopic surgery (LS) has gradually and widely been adopted for the treatment of rectal cancer [6]. Many comparative studies and randomized controlled trials (RCT) have demonstrated that laparoscopic rectal resection is a safe and effective alternative, which has notable superiority of mild trauma, rapid recovery and fewer short-term complications compared with open surgery [7-12]. Abdominoperineal resection (APR) with permanent coloanal is a conventional operation for low rectal cancer [13]. But with the development and advance of surgical technique, especially the introduction of total mesorectal excision (TME) [14], surgeons have paid more attention to performing sphincter preservation. And more patients especially young patients prefer to choose sphincter preservation operation owing to low quality of life after APR [15,16]. However, laparoscopic sphincter-preserving surgery for low rectal cancer in a narrow pelvic cavity is hindered by innately technical difficulties and demanding including rigid instruments, limited two-dimensional vision and range of motion, instability of camera platform and uncontrollable tremor from surgical assistants [17]. Studies have reported that laparoscopic approach has a high conversion rate to open surgery and positive circumferential margin rate [18] and may be associated with increased rates of urogenital dysfunction compared with open low rectal resection in MRC CLASICC trial $[19,20]$.

Robotic-assisted surgery system (RS) as a novel technology is designed to overcome technical limitations of LS by advanced stereoscopic vision, lack of tremor, flexibility of instruments and providing comfortable ergonomics [21,22], which may be beneficial for pelvic autonomic nerve preservation and sphincter preservation. The ROLARR Randomized Clinical Trial has showed that no significant difference was found especially the rate of conversion to open laparotomy between RS and LS [23]. And ROLARR trial evaluated the short-term efficacy and safety of RS in rectal resection including high (upper rectum), low (total rectum) anterior resection and abdominoperineal resection (rectum and perineum). However, only a few studies [24-26] have compared short-term clinical outcomes and complications after surgery between RAS and LAS for low rectal cancer currently. In addition, the majority of studies are small cohorts. As a result, it is hard to reveal the safety and feasibility of RAS in low rectal cancer.

Therefore, the aim of this study was to compare laparoscopic sphincter-preserving surgery (LAS) versus robotic sphincterpreserving surgery (RAS) for the radical resection of low rectal cancer in terms of short-term clinical outcomes, assessment of urogenital function and bowel function and long-term outcomes after surgery.

Page 2/18 


\section{Materials And Methods}

\section{Study design}

This was a single-center retrospective cohort study of consecutive patients diagnosed with low rectal cancer who underwent laparoscopic or robotic sphincter-preserving surgery (RAS 200, LAS 486) between January 1, 2015 and July 1, 2018. All surgical procedures were performed by the same surgical team who have accumulated abundant clinical experience and accomplished their learning curve in robotic and laparoscopic rectal operations [27]. In addition, robotic TME was performed by the same surgeon. Preoperative assessment and postoperative recovery of patients was recorded by surgeons. The questionnaires of assessment of postoperative urogenital and bowel function involving patients' privacy were performed under patients' valid consent by interview with expert research nurses or doctors during out-patient visits or follow-up phone calls. The study protocol was approved by the ethics committees of The First Affiliated Hospital of Anhui Medical University. And the study was conducted after obtaining patients' informed consent.

\section{Study Population and Treatments}

Inclusion criteria of patients were chosen if: (a) adult patients (age $\geq 18$ years) diagnosed with rectal adenocarcinoma histologically; (b) tumor site located within $6 \mathrm{~cm}$ of the anal verge by sigmoidoscopy or rectal magnetic resonance imaging (MRI) examination; (c) clinical T stage (cT) $\otimes \mathrm{T} 4 \mathrm{a}$, negative circumferential margin (CRM) and excluding distant metastasis (M1) or cancer invading adjacent tissues or organs (T4a or T4b) by rectal MRI or abdominal pelvic enhanced computed tomography (CT); (d) ASA classificationखIV and excluding surgical contraindications. The selection of surgical approach was based on a joint decision between surgeon and patient.

All patients underwent routine preoperative examination including digital rectal examination (DRE), sigmoidoscopic biopsy, rectal and hepatic MRI or abdominal pelvic enhanced CT examination, the level of serum hemoglobin, albumin and tumor marker measurement. In addition, patients with locally advanced rectal cancer (cT4aN1-2M0) by MRI or CT examination received neoadjuvant chemoradiotherapy to reduce tumor loading and afford operation possibility. Neoadjuvant chemoradiotherapy needs 2 or 3 cycles ( 3 weeks per cycle) of oxaliplatin or raltitrexed plus capecitabine and radiotherapy (50.4 Gy). Patients who accomplished neoadjuvant chemoradiotherapy underwent the same preoperative examination after 6-8 weeks. Partial patients who met the criteria for radical resection underwent robotic or laparoscopic surgery.

The Da Vinci Si surgical system (Intuitive Surgical) was used for all RAS. Total mesorectal excision (TME) and pelvic autonomic nerve preservation were performed in all patients. All procedures between RAS and LAS were conducted by standard techniques of high quality TME. In addition, the choice of stapled anastomosis or hand-sewn anastomosis depends on the tumor location and intraoperative operation. Temporary ileostomy was conducted under the surgeon's discretion by evaluating the tension of anastomosis and mobilization of splenic flexure. Closure of ileostomy was routinely performed at 3 to 6 months after surgery or after completing postoperative adjuvant chemotherapy or chemoradiotherapy.

\section{Data and Materials}

Study data from consecutive patients with low rectal cancer who underwent robotic or laparoscopic sphincter-preserving surgery in TME between January 2015 and July 2018 in a tertiary hospital of China (The First Affiliated Hospital of Anhui Medical University, Hefei, China) were extracted from computerized patient record system database.

The patient characteristics collected included gender, age, body mass index (BMI), preoperative comorbidity (diabetes), ASA classification, the level of serum hemoglobin, albumin, CEA and CA199, distance from anal verge, clinical tumor-node-metastasis (TNM) stage and neoadjuvant chemoradiotherapy. Intraoperative outcomes included operative time, blood loss, blood transfusion, cases with conversion to laparotomy and temporary ileostomy. Postoperative recovery outcomes included the leaving bed time, time to first flatus and liquid diet, VAS (visual analogue scale) score of day 1 3, Removal time of catheter and drainage cube, total volume of drainage and length of hospital stay. Postoperative complications within 30 days were classified into grade $₫-\otimes$ by Clavien-Dindo classification [28]. Pathologic results included tumor size, histological type, lymph nodes, 
vascular invasion, nerve invasion, tumor deposit, distal resection margin (DRM), positive circumferential resection margin (CRM) and pathologic T/N stage. Thereinto, positive CRM was defined involved if distant with $1 \mathrm{~mm}$ [29].

\section{Assessment of bowel and urogenital function and Follow-up}

A standard questionnaire for assessment of urinary function was conducted based on the International Prostatic Symptom Score (IPSS). Questionnaire includes seven questions associated with voiding function. The score for each item adds up to calculate

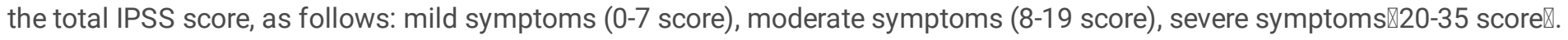

The assessment of male sexual was based on the international index of erectile function (IIEF). The questionnaire of IIEF consists of 15 items involving evaluation of erectile function, orgasmic function, sexual desire, intercourse satisfaction, and overall sexual satisfaction. The Female Sexual Function Index (FSFI) was used to assess female sexual function, which includes the evaluation of desire, arousal, lubrication, orgasm, satisfaction, and pain. Likewise, the score for each item adds up to calculate the total IIEF score or total FSFI score.

Wexner score consisting of five items to assess postoperative bowel function, as follows: gas incontinence, liquid incontinence, solid incontinence, pad wearing and lifestyle alteration. The total score is calculated by adding each item score, with normal ( 0 score), mild incontinence (1-8 score), moderate incontinence (9-14 score), complete incontinence (15-20 score). Follow-up outcomes included postoperative adjuvant treatments, cases with local recurrence, distant metastasis or death and 3-years overall survival rate (OR) and disease-free survival rate (RFS).

\section{Statistical analysis}

Data collected was analyzed by using SPSS 22.0 software (Chicago, IL, USA). The Student t-test or the Mann-Whitney U-test was used for comparisons of qualitative variables, with nonparametric variables expressed by median and range, parametric variables by mean \pm standard deviation $(x \pm s)$. The $X^{2}$ test or Fisher exact test was used for comparisons of categorical variables. Kaplan-Meier method was used to estimate OS and DFS at 1, 3, 5 years after surgery. Cox regression analyses were

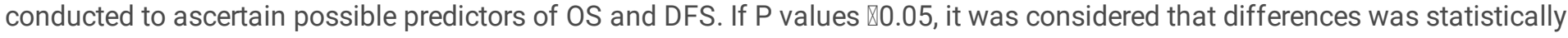
significant.

\section{Results}

Between January 2015 and July 2018, total 686 patients with low rectal cancer who met the incision criteria of rectal incision were enrolled in this study at gastrointestinal surgery department. Of these patients, 200 patients underwent RAS and 486 patients underwent LAS respectively. Preoperative clinical characteristics for the two groups are displayed in Table 1. The distance from the anal verge in the RAS group was significantly lower than LAS group $(5.06 \pm 0.84 \mathrm{~cm}$ vs $5.66 \pm 0.53 \mathrm{~cm}, P \otimes 0.001)$. No significant difference was observed in term of gender, age, ASA classification, NRS 2002 score, comorbidity (diabetes), level of serum hemoglobin, plasma albumin, serum CEA and CA199. Distribution of clinical T-stage, N-stage and TNM-stage, proportion undergoing preoperative neoadjuvant chemoradiotherapy were also similar between two groups. Besides, the total costs were higher in RAS group (53922 \pm 14290 vs $48522 \pm 14290$ ه $\mathrm{P} \otimes 0.001)$.

\section{Short-term outcomes}

The intraoperative outcomes and recovery courses were shown in Table 2 . Only 2 patients $(0.4 \%)$ required conversion to open in the LAS group (one case with narrow pelvis and pelvic adhesions, one case with intraoperative bleeding). The operative time was significantly longer in RAS group ( $249 \pm 64 \mathrm{~min}$ vs $203 \pm 47 \mathrm{~min}, \mathrm{P} \otimes 0.001)$. The estimated intraoperative blood loss was significantly higher in the LAS group $(95 \pm 33 \mathrm{ml}$ vs $82 \pm 49 \mathrm{ml}, \mathrm{P}=0.001)$. A total of 8 patients $(4 \%)$ required blood transfusion in the RAS group, and 18 patients (3.7\%) in the LAS group (P凶0.05). But no significant difference was found between two groups. Temporary ileostomy was conducted in 129 patients (64.5\%) in the RAS group and in 251 patients (51.6\%) in the LAS group respectively $(\mathrm{P} \otimes 0.05)$. No adverse events occurred in two groups during operation. The RAS group was with a shorter time of first flatus and liquid intake $[2(1,3)$ vs $3(2,3), P \llbracket 0.0001 ; 3(2,4)$ vs $4(3,4), P \llbracket 0.0001$, respectively]. The firstly leaving bed time in the RAS group was significantly shorter than LAS group $[2(2,3)$, vs $3(2,3), P \unrhd 0.001]$. The removal time of catheter was shorter in RAS 
group [ $4.9 \pm 1.2$ vs $5.2 \pm 1.3, P=0.004]$. Similarly, the same result of length of hospital stay was observed $(9.5 \pm 4.6$ days vs $11.3 \pm 5.9$ days, $P \otimes 0.001$ ). And there was no significant difference in terms of VAS score, the drainage of cube duration and total volume of drainage.

All of the postoperative complications were shown in Table 2 before discharge in two groups. Totally, 118 complications were occurred, as follows, $32(16 \%)$ in RAS group, $86(17.7 \%)$ in LAS group ( $\mathrm{P}=0.593)$. Among these complications, 1 patient $(0.5 \%)$ died because of cardiovascular accident in RAS group, and 2 patients $(0.4 \%)$ died in LAS group, with one died of cardiovascular accident, the other died of multiple organ failure as a result of anastomotic leakage (P凶0.05). The rate of postoperative urinary retention was higher in LAS group ( $4.1 \%$ vs $3.5 \%, P=0.706)$, but the difference was not statistically significant. And the type of complications was no significant difference between two groups. The Clavien-Dindo classification was used to classify the severity of all complications. And the distribution of severity showed not statistically significant difference between two groups

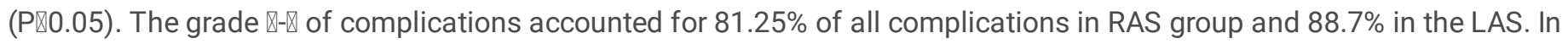
addition, a total of 32 patients $(4.7 \%)$ suffered from anastomotic leakage between two groups, which were treated with conservative treatment except for 6 patients, with 2 patients in the RAS group, and 4 patients in the LAS group (Pख0.05). 2 patients in LAS group and 1 patient in RAS group with postoperative ileus required second operation, and 1 patient with intraabdominal abscess in RAS group experienced relaparotomy within 30 days after surgery.

The pathological results were also shown in Table 2. Median distal resection margins in the RAS group and LAS group were 1.4 $\mathrm{cm}(1.1,1.9)$ and $1.6 \mathrm{~cm}(1,2)$, respectively (Pख0.05). The involved circumferential margin (CRM) was confirmed in two patients in the LAS group (P囚0.05). The R0 resection achieved all cases excepted for 2 patients in LAS group. The tumor size, mean harvested lymph nodes, vascular invasion, nerve invasion, tumor deposit, the distribution of histologic differentiation and clinical TNM stage were similar in the two groups (all, $\mathrm{P} \llbracket 0.05$ ).

\section{Changes in the total IPSS score and Wexner score}

Preoperative and postoperative changes in urinary function and bowel function were both shown in Table 3. A total of 169 patients (84.5\%) in the RAS group received the assessment after surgery, and 404 patients (83.1\%) in the LAS group. Preoperative IPSS scores between LAS and RAS showed no significant difference $(P=0.088)$. The IPSS scores between two groups appreciably increased after postoperative 1 month (Pख0.05). The score decreased significantly after postoperative 3 months in the RAS group [RAS 5, (5,6) vs LAS 7(6 8), P囚0.001]. The difference continued 6 months after surgery between two groups (RAS, 5(4 6) vs LAS, $6(4,7), P \llbracket 0.001)$. At 2 years after surgery, 3 cases (1.7\%) suffered from moderate urinary dysfunction in the RAS group, and 9 cases $(2.2 \%)$ in the LAS group (Pख0.05).

Wexner score results showed increasing trend after surgery and decreased gradually in the recovery course similarly. The scores at 6 months after surgery for the RAS group were significantly lower than LAS group [RAS $0(0.1)$ vs $1(1,3), P \llbracket 0.001]$. The scores recovered approximately normal level at 12 months for the RAS group, but more than 12 months for the LAS group [RAS $0(0,1)$ vs LAS $1(0,1), P \otimes 0.001]$.

\section{Changes in total IIEF scores and FIFS scores}

IIEF scores were analyzed for 121 male patients (RAS 46, LAS 75). Changes in total IIEF scores for male patients were showed in Table 3. The mean total IIEF scores at 6, 12 months after surgery for the RAS group were significantly higher than LAS group [RAS 38.5 \pm 4.5 vs LAS $34.5 \pm 5.8, P \otimes 0.001$; RAS $46.4 \pm 5.9$ vs $41.0 \pm 5.6$, P $₫ 0.001$, respectively]. At 24 months after surgery, 1 patient in the RAS group and 2 patients in the LAS group suffered from erectile dysfunction.

Total 75 female patients (RAS 20, LAS 55) participated in the assessment of sexual function. Total FIFS scores were also presented in Table 3 . The results showed that the recovery of sexual function in the RAS group was accelerated significantly at 3 months after surgery than LAS group (RAS $16.6 \pm 3.7$ vs LAS $14.2 \pm 2.5, P=0.003$ ). And the mean total FIFS scores were significantly higher in the RAS group than LAS group at 6,12 months after surgery (all $\mathrm{P} \otimes 0.05$ ).

\section{Long-term outcomes}

Page 5/18 
The median follow-up was 53.2 months for the RAS group and 54.1 months for the LAS group respectively. OS and DFS at 1, 3, 5 years after surgery were similar between two groups. The Kaplan-Meier curve of OS and DFS was presented in Figs. 1, 2 respectively. A total of 69 patients $(10.1 \%)$ suffered from distant metastases, including liver $(n=34)$, pulmonary $(n=34)$ and brain $(n=1)$, with no significant difference between RAS group and LAS group. In addition, 19 patients (9.5\%) in the RAS group and 50 patients $(10.3 \%)$ in the LAS group were diagnosed with local recurrence around surgery position $(P=0.883)$. Cox regression analyses presented in Table 4. indicated that the positive CRM, pT stage, positive lymph nodes (pN+) and age may be the significant predictors of OS after surgery. The DFS showed the similar results except for age.

\section{Discussion}

The sphincter-preserving operation for low rectal cancer was widely adopted by surgeons. Relevant literatures $[30,31]$ have indicated that it is safe and feasible in oncology and technology and is superior to abdominoperineal resection (APR) on longterm quality of life. And with the development of minimally invasive surgery, laparoscopy improved short-term outcomes and shortened the time of recovery after surgery compared to conventional open sphincter-preserving total mesorectal excision for low rectal cancer [32,33]. However, the technical limitations of laparoscopy including rigid instruments, 2- dimensional (2D) vision, instability of camera platform and uncontrollable tremor hinder operations in deep narrow pelvis cavity and increase the rate of positive CRM on pathological outcomes $[17,20]$.

Robotic surgery may overcome these limitations based on technical strengths $[21,22]$ which may improve lymph nodes dissection, vascular protection and nerve preservation. In addition, pathological studies have showed that the distal margin within $1 \mathrm{~cm}$ did not jeopardize oncologic safety [34], which provided theoretical foundation in the sphincter-preserving operation for ultra-lower rectum cancer. Therefore, robotic approach has been used to perform sphincter-preserving procedures for the treatment of low rectal cancer.

Many studies [23,35-38] have been demonstrated that robotic approach in rectal cancer have some advantages in intraoperative outcomes and short-term recovery, which included less blood loss, fine technical operability for lateral and inferior mesenteric artery (IMA) root lymph nodes dissection, low conversion rate, earlier flatus and liquid intake and shorter length of stay, although limited by longer operating time and high cost. In this study, the short-term results are consistent with current literatures.

However, the main two concerns about sphincter-preserving TME procedures are recovery of urogenital and bowel function after surgery, respectively. Heald et al. [14] highlighted the importance of nerve preservation and prevention of local recurrence. Robotic surgery may decrease the direct injury or avulsion of hypogastric nerve plexus through a magnified stereoscopic vision to identify and choose the avascular plane during pelvic dissection [39], which further avoid postoperative urinary and sexual dysfunction. Kim [39] et al. reported that robotic TME excision was related to earlier recovery of normal voiding and male sexual function with erectile function and sexual desire compared to laparoscopic TME. The current meta-analysis [40-42] indicated that robotic rectal surgery may provide short-term advantages in the postoperative recovery of urinary and sexual function. The present study has shown that robotic approach has lower rate of urinary retention within 30 days, higher total IPSS scores at 3 months, better IIEF scores at 6 months and superior FIFS scores at 3 months than laparoscopic approach after surgery. And there were significant differences between both groups. But at 2 years after surgery, no significant differences were found when compared urogenital function in male and female patients between two groups.

Another concern is the recovery of postoperative bowel function. The mechanism impairing anorectal function is damage to the internal anal sphincter, which consist of direct injury by operating instruments and injury of pelvic splanchnic nerves [43]. Identified risks of postoperative bowel dysfunction are perioperative radiotherapy and low location of anastomosis [44,45]. Several studies $[46,47]$ have indicated a correlation between use of temporary ileostomy and bowel dysfunction. However, the results were influenced by confounding factors including adjuvant radiotherapy and low site tumor from anal edge. The available evidence suggested that robotic TME could preserve anorectal function well than open TME or laparoscopic TME [48]. In this present study, RAS enabled quick and better recovery of bowel function at 6 months after surgery compared to LAS.

Furthermore, the oncologic safety of robotic rectal surgery seemed to be demonstrated by several studies in long-term survival follow-up. Feroci [49] et al. compared 3-year OS and DFS rates after surgery between robotic surgery and laparoscopic surgery for 
middle-low rectal cancer. The results showed no significant difference. Cho [50] et al. reported that the 5-year OS rates between two groups had not significant difference. Kim et al. found that the 5-year OS rates were lower in laparoscopic surgery than robotic surgery, but the differences were not statistically significant. Similarly, the present study demonstrates that no differences between different surgical approach in OS and DFS at 3 and 5 years. And the positive CRM, pT stage, pN stage may be the negative predictors of OS and DFS, but postoperative adjuvant radiotherapy is positive factor by Cox regression analysis.

However, there exists some limitations in present study. Firstly, potential selection bias and reporting error cannot be excluded. For example, a significant number of ultra-low tumor localizations is included in RAS group compared to LAS group, which may be bad for the evaluation of anorectal function after surgery in RAS group. Secondly, this study is not a randomized trail and it was based on a prospective and single-center experience in a tertiary colorectal treatment center. Intraoperative outcomes were influenced by the surgeons' learning curve, skills and experience in both RAS and LAS. The respective operations may be quite different. In addition, the assessment of urogenital and bowel function was conducted by standard questionnaires. Results involved in patients' privacy may not be quite accurate.

In conclusion, robotic and laparoscopic sphincter-preserving surgery can be both performed safely and effectively in low rectal cancer. Robotic approach is superior to laparoscopic approach in short-term outcomes and protection of urogenital and anorectal function.

\section{Declarations}

\section{Conflict of interest: No.}

\section{Availability of data and materials:}

The datasets supporting the conclusion of this article are included within the article.

\section{Human participants and animal rights}

This article does not contain any studies with human participants or animals

performed by any of the authors.

\section{Ethics approval and consent to participate}

The study protocol was approved by the ethics committees of The First Affiliated Hospital of Anhui Medical University.

\section{Consent for publication}

Not applicable.

\section{Author Contributions:}

Yongxiang Li, Bo Yang, ShangXin Zhang, Xiaodong Yang, Yigao Wang and Jian Zhao were all involved with the conception and design of the study. Bo Yang, Jian Zhao and Deguan Li participated in data acquisition, analysis and interpretation. Bo Yang wrote the main manuscript text and also prepared tables 1-4 and figures 1-2. All authors reviewed the manuscript.

Funding: This work was supported by National Natural Science Foundation of China(No.81874063).

Acknowledgements: First Affiliated Hospital of Anhui Medical University department of general of surgery; The Ethics Committees of The First Affiliated Hospital of Anhui Medical University; This work was supported by National Natural Science Foundation of China(No.81874063).

\section{References}


1. Ferlay J , Colombet M, Soerjomataram I, et al. Cancer incidence and mortality patterns in Europe: Estimates for 40 countries and 25 major cancers in 2018[J]. European Journal of Cancer, 2018, 103:356-387.

2. Miller K D , M Fidler-Benaoudia, Keegan T H, et al. Cancer statistics for adolescents and young adults, 2020[J]. CA: A Cancer Journal for Clinicians.

3. Siegel R L, Miller K D , Jemal A . Cancer statistics, 2020[J]. CA: A Cancer Journal for Clinicians, 2020, 70(1).

4. Jacobs M , Verdeja J C , Goldstein H S . Minimally Invasive Colon Resection (Laparoscopic Colectomy)[J]. Surgical Laparoscopy Endoscopy \& Percutaneous Techniques, 1991, 1.

5. Hase K, Shatney $\mathrm{CH}$, Mochizuki $\mathrm{H}$, et al. Long-term results of curative resection of "minimally invasive" colorectal cancer[J]. Diseases of the Colon \& Rectum, 1995, 38(1):19-26.

6. Davis C H, Gaglani T, Moore L W , et al. Trends and Outcomes in Laparoscopic versus Open Surgery for Rectal Cancer from 2005 to 2016 Using the ACS-NSQIP Database, a Retrospective Cohort Study[J]. International Journal of Surgery (London, England), 2019.

7. Kellokumpu I H, Kairaluoma M I, Nuorva K P , et al. Short- and Long-term Outcome Following Laparoscopic Versus Open Resection for Carcinoma of the Rectum in the Multimodal Setting[J]. Diseases of the Colon \& Rectum, 2012, 55(8):854-863.

8. Laurent C , Leblanc F , P Wütrich, et al. Laparoscopic Versus Open Surgery for Rectal Cancer: Long-Term Oncologic Results[J]. Annals of Surgery, 2009, 250(1):54-61.

9. Keskin M , Akici M , Agcaoglu O , et al. Open Versus Laparoscopic Surgery for Rectal Cancer: Single-Center Results of 587 Cases[J]. Surgical Laparoscopy Endoscopy \& Percutaneous Techniques, 2016, 26.

10. Hgm V D P M , Haglind E, Cuesta M A, et al. Laparoscopic versus open surgery for rectal cancer (COLOR II): short-term outcomes of a randomised, phase 3 trial.[J]. Lancet Oncology, 2013, 14(3):210-218.

11. Jeong SY, Park JW, Nam BH, Kim S, Kang SB, Lim SB, Choi HS, Kim DW, Chang HJ, Kim DY, Jung KH, Kim TY, Kang GH, Chie EK, Kim SY, Sohn DK, Kim DH, Kim JS, Lee HS, Kim JH, Oh JH. Open versus laparoscopic surgery for mid-rectal or low-rectal cancer after neoadjuvant chemoradiotherapy (COREAN trial): survival outcomes of an open-label, non-inferiority, randomised controlled trial. Lancet Oncol. 2014 Jun;15(7):767-74. doi: 10.1016/S1470-2045(14)70205-0. Epub 2014 May 15. Erratum in: Lancet Oncol. 2016 Jul;17 (7):e270. PMID: 24837215.

12. Bonjer HJ, Deijen CL, Abis GA, Cuesta MA, van der Pas MH, de Lange-de Klerk ES, Lacy AM, Bemelman WA, Andersson J, Angenete E, Rosenberg J, Fuerst A, Haglind E; COLOR II Study Group. A randomized trial of laparoscopic versus open surgery for rectal cancer. N Engl J Med. 2015 Apr 2;372(14):1324-32. doi: 10.1056/NEJMoa1414882. PMID: 25830422.

13. Glynne-Jones R, Wyrwicz L, Tiret E, Brown G, Rödel C, Cervantes A, Arnold D; ESMO Guidelines Committee. Rectal cancer: ESMO Clinical Practice Guidelines for diagnosis, treatment and follow-up. Ann Oncol. 2018 Oct 1;29(Suppl 4):iv263. doi: 10.1093/annonc/mdy161. Erratum for: Ann Oncol. 2017 Jul 1;28(suppl_4):iv22-iv40. PMID: 29741565.

14. Heald RJ, Ryall RD. Recurrence and survival after total mesorectal excision for rectal cancer. Lancet. 1986 Jun 28;1(8496):1479-82. doi: 10.1016/s0140-6736(86)91510-2. PMID: 2425199.

15. Shahjehan F, Kasi PM, Habermann E, Day CN, Colibaseanu DT, Mathis KL, Larson DW, Merchea A. Trends and outcomes of sphincter-preserving surgery for rectal cancer: a national cancer database study. Int J Colorectal Dis. 2019 Feb;34(2):239245. doi: 10.1007/s00384-018-3171-y. Epub 2018 Oct 2. PMID: 30280252.

16. Hawkins AT, Albutt K, Wise PE, Alavi K, Sudan R, Kaiser AM, Bordeianou L; Continuing Education Committee of the SSAT. Abdominoperineal Resection for Rectal Cancer in the Twenty-First Century: Indications, Techniques, and Outcomes. J Gastrointest Surg. 2018 Aug;22(8):1477-1487. doi: 10.1007/s11605-018-3750-9. Epub 2018 Apr 16. PMID: 29663303.

17. Fleshman J, Branda M, Sargent DJ, Boller AM, George V, Abbas M, Peters WR Jr, Maun D, Chang G, Herline A, Fichera A, Mutch M, Wexner S, Whiteford M, Marks J, Birnbaum E, Margolin D, Larson D, Marcello P, Posner M, Read T, Monson J, Wren SM, Pisters PW, Nelson H. Effect of Laparoscopic-Assisted Resection vs Open Resection of Stage II or III Rectal Cancer on Pathologic Outcomes: The ACOSOG Z6051 Randomized Clinical Trial. JAMA. 2015 Oct 6;314(13):1346-55. doi: 10.1001/jama.2015.10529. PMID: 26441179; PMCID: PMC5140087.

18. Jayne DG, Guillou PJ, Thorpe H, Quirke P, Copeland J, Smith AM, Heath RM, Brown JM; UK MRC CLASICC Trial Group. Randomized trial of laparoscopic-assisted resection of colorectal carcinoma: 3-year results of the UK MRC CLASICC Trial 
Group. J Clin Oncol. 2007 Jul 20;25(21):3061-8. doi: 10.1200/JC0.2006.09.7758. PMID: 17634484.

19. Jayne DG, Brown JM, Thorpe H, Walker J, Quirke P, Guillou PJ. Bladder and sexual function following resection for rectal cancer in a randomized clinical trial of laparoscopic versus open technique. Br J Surg. 2005 Sep;92(9):1124-32. doi: 10.1002/bjs.4989. PMID: 15997446.

20. Guillou PJ, Quirke P, Thorpe H, Walker J, Jayne DG, Smith AM, Heath RM, Brown JM; MRC CLASICC trial group. Short-term endpoints of conventional versus laparoscopic-assisted surgery in patients with colorectal cancer (MRC CLASICC trial): multicentre, randomised controlled trial. Lancet. 2005 May 14-20;365(9472):1718-26. doi: 10.1016/S0140-6736(05)66545-2. PMID: 15894098.

21. Pigazzi A, Ellenhorn JD, Ballantyne GH, Paz IB. Robotic-assisted laparoscopic low anterior resection with total mesorectal excision for rectal cancer. Surg Endosc. 2006 Oct;20(10):1521-5. doi: 10.1007/s00464-005-0855-5. Epub 2006 Aug 1. PMID: 16897284.

22. Park S, Kim NK. The Role of Robotic Surgery for Rectal Cancer: Overcoming Technical Challenges in Laparoscopic Surgery by Advanced Techniques. J Korean Med Sci. 2015 Jul;30(7):837-46. doi: 10.3346/jkms.2015.30.7.837. Epub 2015 Jun 10. PMID: 26130943; PMCID: PMC4479934.

23. Jayne D, Pigazzi A, Marshall H, Croft J, Corrigan N, Copeland J, Quirke P, West N, Rautio T, Thomassen N, Tilney H, Gudgeon M, Bianchi PP, Edlin R, Hulme C, Brown J. Effect of Robotic-Assisted vs Conventional Laparoscopic Surgery on Risk of Conversion to Open Laparotomy Among Patients Undergoing Resection for Rectal Cancer: The ROLARR Randomized Clinical Trial. JAMA. 2017 Oct 24;318(16):1569-1580. doi: 10.1001/jama.2017.7219. PMID: 29067426; PMCID: PMC5818805.

24. Park JS, Choi GS, Lim KH, Jang YS, Jun SH. Robotic-assisted versus laparoscopic surgery for low rectal cancer: casematched analysis of short-term outcomes. Ann Surg Oncol. 2010 Dec;17(12):3195-202. doi: 10.1245/s10434-010-1162-5. Epub 2010 Jun 30. PMID: 20589436.

25. Kim MJ, Park SC, Park JW, Chang HJ, Kim DY, Nam BH, Sohn DK, Oh JH. Robot-assisted Versus Laparoscopic Surgery for Rectal Cancer: A Phase II Open Label Prospective Randomized Controlled Trial. Ann Surg. 2018 Feb;267(2):243-251. doi: 10.1097/SLA.0000000000002321. PMID: 28549014.

26. Ishihara S, Kiyomatsu T, Kawai K, Tanaka T, Hata K, Kazama S, Sunami E, Nozawa H, Watanabe T. The short-term outcomes of robotic sphincter-preserving surgery for rectal cancer: comparison with open and laparoscopic surgery using a propensity score analysis. Int J Colorectal Dis. 2018 Aug;33(8):1047-1055. doi: 10.1007/s00384-018-3056-0. Epub 2018 Apr 23. PMID: 29687373.

27. Olthof PB, Giesen LJX, Vijfvinkel TS, Roos D, Dekker JWT. Transition from laparoscopic to robotic rectal resection: outcomes and learning curve of the initial 100 cases. Surg Endosc. 2021 Jun;35(6):2921-2927. doi: 10.1007/s00464-020-07731-0. Epub 2020 Jun 18. PMID: 32556694; PMCID: PMC8116275.

28. Dindo D, Demartines N, Clavien PA. Classification of surgical complications: a new proposal with evaluation in a cohort of 6336 patients and results of a survey. Ann Surg. 2004 Aug;240(2):205-13. doi: 10.1097/01.sla.0000133083.54934.ae. PMID: 15273542; PMCID: PMC1360123.

29. Adam IJ, Mohamdee MO, Martin IG, Scott N, Finan PJ, Johnston D, Dixon MF, Quirke P. Role of circumferential margin involvement in the local recurrence of rectal cancer. Lancet. 1994 Sep 10;344(8924):707-11. doi: 10.1016/s01406736(94)92206-3. PMID: 7915774.

30. Klose J, Tarantino I, Kulu Y, Bruckner T, Trefz S, Schmidt T, Schneider M, Hackert T, Büchler MW, Ulrich A. Sphincter-Preserving Surgery for Low Rectal Cancer: Do We Overshoot the Mark? J Gastrointest Surg. 2017 May;21(5):885-891. doi: 10.1007/s11605-016-3339-0. Epub 2016 Dec 15. PMID: 27981492.

31. Bordeianou L, Maguire LH, Alavi K, Sudan R, Wise PE, Kaiser AM. Sphincter-sparing surgery in patients with low-lying rectal cancer: techniques, oncologic outcomes, and functional results. J Gastrointest Surg. 2014 Jul;18(7):1358-72. doi: 10.1007/s11605-014-2528-y. Epub 2014 May 13. PMID: 24820137; PMCID: PMC4057635.

32. Ng SS, Lee JF, Yiu RY, Li JC, Hon SS, Mak TW, Ngo DK, Leung WW, Leung KL. Laparoscopic-assisted versus open total mesorectal excision with anal sphincter preservation for mid and low rectal cancer: a prospective, randomized trial. Surg Endosc. 2014 Jan;28(1):297-306. doi: 10.1007/s00464-013-3187-x. Epub 2013 Sep 7. PMID: 24013470.

Page 9/18 
33. Zhou ZG, Hu M, Li Y, Lei WZ, Yu YY, Cheng Z, Li L, Shu Y, Wang TC. Laparoscopic versus open total mesorectal excision with anal sphincter preservation for low rectal cancer. Surg Endosc. 2004 Aug;18(8):1211-5. doi: 10.1007/s00464-003-9170-1. Epub 2004 Jun 23. PMID: 15457380.

34. Bujko K, Rutkowski A, Chang GJ, Michalski W, Chmielik E, Kusnierz J. Is the 1-cm rule of distal bowel resection margin in rectal cancer based on clinical evidence? A systematic review. Ann Surg Oncol. 2012 Mar;19(3):801-8. doi: 10.1245/s10434011-2035-2. Epub 2011 Aug 31. PMID: 21879269; PMCID: PMC3278608.

35. Lin S, Jiang HG, Chen ZH, Zhou SY, Liu XS, Yu JR. Meta-analysis of robotic and laparoscopic surgery for treatment of rectal cancer. World J Gastroenterol. 2011 Dec 21;17(47):5214-20. doi: 10.3748/wjg.v17.i47.5214. PMID: 22215947; PMCID: PMC3243889.

36. Simillis C, Lal N, Thoukididou SN, Kontovounisios C, Smith JJ, Hompes R, Adamina M, Tekkis PP. Open Versus Laparoscopic Versus Robotic Versus Transanal Mesorectal Excision for Rectal Cancer: A Systematic Review and Network Meta-analysis. Ann Surg. 2019 Jul;270(1):59-68. doi: 10.1097/SLA.0000000000003227. PMID: 30720507.

37. Song SH, Choi GS, Kim HJ, Park JS, Park SY, Lee SM, Choi JA, Seok HA. Long-term clinical outcomes of total mesorectal excision and selective lateral pelvic lymph node dissection for advanced low rectal cancer: a comparative study of a robotic versus laparoscopic approach. Tech Coloproctol. 2021 Apr;25(4):413-423. doi: 10.1007/s10151-020-02383-7. Epub 2021 Feb 16. PMID: 33594627.

38. Shin US, Nancy You Y, Nguyen AT, Bednarski BK, Messick C, Maru DM, Dean EM, Nguyen ST, Hu CY, Chang GJ. Oncologic Outcomes of Extended Robotic Resection for Rectal Cancer. Ann Surg Oncol. 2016 Jul;23(7):2249-57. doi: 10.1245/s10434016-5117-3. Epub 2016 Feb 8. PMID: 26856720.

39. Kim JY, Kim NK, Lee KY, Hur H, Min BS, Kim JH. A comparative study of voiding and sexual function after total mesorectal excision with autonomic nerve preservation for rectal cancer: laparoscopic versus robotic surgery. Ann Surg Oncol. 2012 Aug;19(8):2485-93. doi: 10.1245/s10434-012-2262-1. Epub 2012 Mar 21. PMID: 22434245.

40. Tang X, Wang Z, Wu X, Yang M, Wang D. Robotic versus laparoscopic surgery for rectal cancer in male urogenital function preservation, a meta-analysis. World J Surg Oncol. 2018 Oct 2;16(1):196. doi: 10.1186/s12957-018-1499-y. PMID: 30285780; PMCID: PMC6169007.

41. Wee IJY, Kuo LJ, Ngu JC. Urological and sexual function after robotic and laparoscopic surgery for rectal cancer: A systematic review, meta-analysis and meta-regression. Int J Med Robot. 2021 Feb;17(1):1-8. doi: 10.1002/rcs.2164. Epub 2020 Sep 17. PMID: 32945090.

42. Fleming CA, Cullinane C, Lynch N, Killeen S, Coffey JC, Peirce CB. Urogenital function following robotic and laparoscopic rectal cancer surgery: meta-analysis. Br J Surg. 2021 Mar 12;108(2):128-137. doi: 10.1093/bjs/znaa067. PMID: 33711141.

43. Bryant CL, Lunniss PJ, Knowles CH, Thaha MA, Chan CL. Anterior resection syndrome. Lancet Oncol. 2012 Sep;13(9):e403-8. doi: 10.1016/S1470-2045(12)70236-X. PMID: 22935240.

44. Hughes DL, Cornish J, Morris C; LARRIS Trial Management Group. Functional outcome following rectal surgery-predisposing factors for low anterior resection syndrome. Int J Colorectal Dis. 2017 May;32(5):691-697. doi: 10.1007/s00384-017-2765-0. Epub 2017 Jan 27. PMID: 28130593.

45. Sun W, Dou R, Chen J, Lai S, Zhang C, Ruan L, Kang L, Deng Y, Lan P, Wang L, Wang J. Impact of Long-Course Neoadjuvant Radiation on Postoperative Low Anterior Resection Syndrome and Quality of Life in Rectal Cancer: Post Hoc Analysis of a Randomized Controlled Trial. Ann Surg Oncol. 2019 Mar;26(3):746-755. doi: 10.1245/s10434-018-07096-8. Epub 2018 Dec 7. PMID: 30536129.

46. Cheong C, Oh SY, Choi SJ, Suh KW. Ultralow Anterior Resection and Coloanal Anastomosis for Low-Lying Rectal Cancer: An Appraisal Based on Bowel Function. Dig Surg. 2019;36(5):409-417. doi: 10.1159/000490899. Epub 2018 Jul 10. PMID: 29990965.

47. Liu F, Guo P, Shen Z, Gao Z, Wang S, Ye Y. [Risk factor analysis of low anterior resection syndrome after anal sphincter preserving surgery for rectal carcinoma]. Zhonghua Wei Chang Wai Ke Za Zhi. 2017 Mar 25;20(3):289-294. Chinese. PMID: 28338162. 
48. Grass JK, Chen CC, Melling N, Lingala B, Kemper M, Scognamiglio P, Persiani R, Tirelli F, Caricato M, Capolupo GT, Izbicki JR, Perez DR. Robotic rectal resection preserves anorectal function: systematic review and meta-analysis. Int J Med Robot. 2021 Aug 31:e2329. doi: 10.1002/rcs.2329. Epub ahead of print. PMID: 34463416.

49. Feroci F, Vannucchi A, Bianchi PP, Cantafio S, Garzi A, Formisano G, Scatizzi M. Total mesorectal excision for mid and low rectal cancer: Laparoscopic vs robotic surgery. World J Gastroenterol. 2016 Apr 7;22(13):3602-10. doi: 10.3748/wjg.v22.i13.3602. PMID: 27053852; PMCID: PMC4814646.

50. Cho MS, Baek SJ, Hur H, Min BS, Baik SH, Lee KY, Kim NK. Short and long-term outcomes of robotic versus laparoscopic total mesorectal excision for rectal cancer: a case-matched retrospective study. Medicine (Baltimore). 2015 Mar;94(11):e522. doi: 10.1097/MD.0000000000000522. PMID: 25789947; PMCID: PMC4602485.

\section{Tables}

Table 1: Clinical characteristics 


\begin{tabular}{|c|c|c|c|}
\hline Variables & RAS & LAS & $P$ \\
\hline Total patients,n & 200 & 486 & \\
\hline Gender (male,\%) & $121(60.5)$ & $302(62.1)$ & 0.688 \\
\hline 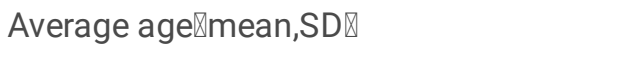 & $58.4 \pm 11.8$ & $59.8 \pm 11.5$ & 0.149 \\
\hline Body mass index $₫$ mean,SD & $23.1 \pm 3.1$ & $22.9 \pm 3.5$ & 0.402 \\
\hline \multicolumn{4}{|l|}{ ASA classification } \\
\hline \multirow{3}{*}{ 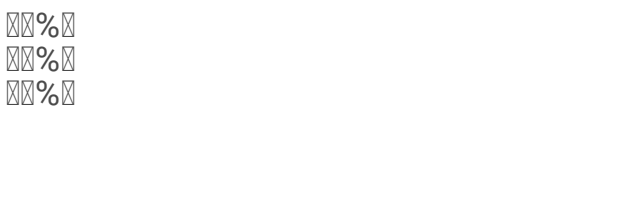 } & 26(13) & $52(10.7)$ & \multirow[t]{3}{*}{0.335} \\
\hline & $134(67)$ & $353(72.6)$ & \\
\hline & $40(20)$ & $81(16.7)$ & \\
\hline NRS2002 score (median,IQR) & $2(2,3)$ & $2(2,3)$ & 0.408 \\
\hline Diabetes(yes,\%) & $26(13)$ & $54(11.1)$ & 0.484 \\
\hline  & $130.9 \pm 15.4$ & $129.5 \pm 15.3$ & 0.263 \\
\hline Level of plasma albumin(g/L,mean,SD) & $43.2 \pm 7.1$ & $42.7 \pm 3.6$ & 0.163 \\
\hline Level of CEA ( $\geq 5 \mathrm{ng} / \mathrm{ml}, \%$ ) & $49(24.5)$ & 154(31.7) & 0.061 \\
\hline Level of CA199 ( $\geq 36 \mathrm{u} / \mathrm{ml}, \%)$ & 18(9) & $58(11.9)$ & 0.266 \\
\hline Distance from anal edge $(\mathrm{cm}$, mean,SD) & $5.06 \pm 0.84$ & $5.66 \pm 0.53$ & $\varangle 0.0001$ \\
\hline \multicolumn{4}{|l|}{ MRI cT stage, N(\%) } \\
\hline \multirow{3}{*}{$\begin{array}{l}\text { T1(\%) } \\
\text { T2(\%) } \\
\text { T3(\%) }\end{array}$} & 26(13) & $59(12.1)$ & \multirow[t]{3}{*}{0.738} \\
\hline & $117(58.5)$ & $274(56.4)$ & \\
\hline & $57(28.5)$ & 153(31.5) & \\
\hline \multicolumn{4}{|l|}{ MRI cN stage, N(\%) } \\
\hline \multirow{3}{*}{$\begin{array}{l}\text { N0(\%) } \\
\text { N1(\%) } \\
\text { N2(\%) }\end{array}$} & $126(63)$ & $336(69.1)$ & \multirow[t]{3}{*}{0.297} \\
\hline & $43(21.5)$ & $87(17.9)$ & \\
\hline & $31(15.5)$ & $63(13)$ & \\
\hline \multicolumn{3}{|l|}{ MRI cTNM stage, N(\%) } & \multirow[t]{4}{*}{0.464} \\
\hline$\bigotimes(\%)$ & $99(49.5)$ & $250(51.4)$ & \\
\hline$\bigotimes(\%)$ & $39(19.5)$ & $107(22)$ & \\
\hline$\bigotimes(\%)$ & $62(31)$ & $129(26.5)$ & \\
\hline Neoadjuvant Chemoradiotherapy (\%) & 21(10.5) & $43(8.8)$ & 0.441 \\
\hline Total hospitalization costs ( ()$\otimes$ mean(SD) & $53922 \pm 14290$ & $48522 \pm 17466$ & $\varangle 0.0001$ \\
\hline
\end{tabular}

RAS: Robotic-assisted surgery group. LAS: laparoscopic-assisted surgery group. NRS: Nutritional Risk Screening. SD: standard deviation. IQR: Inter Quartile range. MRI: Magnetic Resonance Imaging.

Table 2: Intraoperative, postoperative recovery and pathological outcomes 


\begin{tabular}{|c|c|c|c|}
\hline Variables & RAS $(n=200)$ & LAS $(n=484)$ & $\mathrm{P}$ \\
\hline Operative time(min,mean,SD) & $249 \pm 64$ & $203 \pm 47$ & $\otimes 0.0001$ \\
\hline Intraoperative blood loss, mean(SD), ml & $82 \pm 49$ & $95 \pm 32$ & 0.001 \\
\hline Blood transfusion (yes, \%) & $8(4)$ & 18(3.7) & 0.765 \\
\hline Conversion to laparotomy & $0(0)$ & $2(0.4)$ & 1 \\
\hline Temporary ileostomy (yes,\%) & $129(64.5)$ & $251(51.6)$ & 0.002 \\
\hline The leaving bed time(days,median,IQR) & $2(2,3)$ & $3(2,3)$ & $\otimes 0.0001$ \\
\hline Time to first flatus, Days, median(P25,P75,IQR) & $2(1,3)$ & $3(2,3)$ &  \\
\hline Time to liquid diet, Days, median(P25,P75,IQR) & $3(2,4)$ & $4(3,4)$ & $\otimes 0.0001$ \\
\hline \multicolumn{4}{|l|}{ VAS score, median(P25,P75,IQR) } \\
\hline \multirow{3}{*}{$\begin{array}{l}\text { Day } 1 \\
\text { Day } 2 \\
\text { Day } 3\end{array}$} & $2(1,2)$ & $2(1,2)$ & 0.624 \\
\hline & $1(1,2)$ & $1(1,2)$ & 0.54 \\
\hline & $1(1,1)$ & $1(1,1)$ & 0.738 \\
\hline Removal time of catheter, Days, mean(SD) & $4.9 \pm 1.2$ & $5.2 \pm 1.3$ & 0.004 \\
\hline Volume of drainage, $\mathrm{ml}$, mean(SD) & $209 \pm 63$ & $222 \pm 100$ & 0.083 \\
\hline The drainage of cube duration, Days, mean(SD) & $5.7 \pm 1.3$ & $5.9 \pm 1.6$ & 0.168 \\
\hline Postoperative length of stay, Days, mean(SD) & $9.5 \pm 4.6$ & $11.3 \pm 5.9$ & $凶 0.0001$ \\
\hline Overall complications, $\mathrm{n}(\%)$ & $32(16)$ & $86(17.7)$ & 0.593 \\
\hline Anastomotic leakage(\%) & $8(4)$ & $24(4.9)$ & 0.596 \\
\hline Anastomotic and abdominal bleeding(\%) & $2(1)$ & $5(1)$ & 1 \\
\hline Wound infection(\%) & $2(1)$ & $4(0.8)$ & 1 \\
\hline Abdominal infection(\%) & $1(0.5)$ & $5(1)$ & 0.677 \\
\hline Pulmonary infection(\%) & $3(1.5)$ & $10(2.1)$ & 0.765 \\
\hline Urinary infection(\%) & $1(0.5)$ & $5(1)$ & 0.677 \\
\hline Urinary retention(\%) & $7(3.5)$ & $20(4.1)$ & 0.706 \\
\hline Cardiovascular accident(\%) & $1(0.5)$ & $1(0.2)$ & 0.498 \\
\hline Venous thromboembolism (\%) & $0(0)$ & $1(0.2)$ & 1 \\
\hline Ileus(\%) & $7(3.5)$ & $11(2.3)$ & 0.357 \\
\hline \multicolumn{4}{|l|}{ Clavien-Dindo classification } \\
\hline \multirow{5}{*}{$\begin{array}{l}\mathbb{\Delta}(\%) \\
\nabla(\%) \\
\nabla(\%) \\
\nabla(\%) \\
\nabla(\%)\end{array}$} & $10(5)$ & $24(4.9)$ & \multirow[t]{5}{*}{0.887} \\
\hline & $16(8)$ & $52(10.7)$ & \\
\hline & $4(2)$ & $6(1.2)$ & \\
\hline & $1(0.5)$ & $2(0.4)$ & \\
\hline & $1(0.5)$ & $2(0.4)$ & \\
\hline Tumor size, $\mathrm{cm}$, mean(SD) & $3.95 \pm 1.30$ & $4.05 \pm 1.33$ & 0.345 \\
\hline
\end{tabular}




\begin{tabular}{|c|c|c|c|}
\hline \multirow{4}{*}{$\begin{array}{l}\text { Well differentiated adenocarcinoma } \\
\text { Moderately differentiated adenocarcinoma } \\
\text { Poorly differentiated adenocarcinoma } \\
\text { Mucinous adenocarcinoma }\end{array}$} & $10(5)$ & $27(5.6)$ & \multirow[t]{4}{*}{0.319} \\
\hline & $160(80)$ & $361(74.3)$ & \\
\hline & $18(9)$ & $49(10.1)$ & \\
\hline & $12(6)$ & $49(10.1)$ & \\
\hline Number of Harvested lymph nodes, mean(SD) & $13.6 \pm 3.7$ & $14.0 \pm 3.7$ & 0.169 \\
\hline Vascular invasion, n(\%) & 118(59) & $291(59.9)$ & 0.832 \\
\hline Nerve invasion, $\mathrm{n}(\%)$ & $63(31.5)$ & $126(25.9)$ & 0.138 \\
\hline Tumor deposit,N(\%) & $55(27.5)$ & $137(28.2)$ & 0.855 \\
\hline Distal resection margin(cm, median,IQR) & $1.4(1.1,1.875)$ & $1.6(1,2)$ & 0.004 \\
\hline Positive Circumferential resection margin, n(\%) & $1(0.5)$ & $3(0.6)$ & 1 \\
\hline Quality of the mesorectal excision R0 resection,n(\%) & $200(100)$ & $484(99.6)$ & 1 \\
\hline \multicolumn{4}{|l|}{ pT stage,N(\%) } \\
\hline \multirow{5}{*}{$\begin{array}{l}\text { Tis } \\
\text { T1 } \\
\text { T2 } \\
\text { T3 } \\
\text { T4a } \\
\text { T4b }\end{array}$} & $6(3)$ & $12(2.5)$ & \multirow[t]{5}{*}{0.569} \\
\hline & $24(12)$ & $49(10.1)$ & \\
\hline & $58(29)$ & $120(24.7)$ & \\
\hline & $106(53)$ & $292(60.1)$ & \\
\hline & $6(3)$ & $13(2.7)$ & \\
\hline \multicolumn{4}{|l|}{ pN stage,N(\%) } \\
\hline \multirow{6}{*}{$\begin{array}{l}\text { No } \\
\text { N1a } \\
\text { N1b } \\
\text { N1c } \\
\text { N2a } \\
\text { N2b }\end{array}$} & $121(60.5)$ & $277(57)$ & \multirow[t]{6}{*}{0.48} \\
\hline & $21(10.5)$ & $46(9.5)$ & \\
\hline & $24(12)$ & $59(12.1)$ & \\
\hline & $13(6.5)$ & $25(5.1)$ & \\
\hline & $11(5.5)$ & $35(7.2)$ & \\
\hline & $10(5)$ & $44(9.1)$ & \\
\hline \multicolumn{4}{|l|}{ pTNM stage,N(\%) } \\
\hline ૫ & 67(33.5) & $132(27.2)$ & \multirow[t]{3}{*}{0.251} \\
\hline ૫ & $56(28)$ & $150(30.9)$ & \\
\hline$\square$ & 77(38.5) & $204(42)$ & \\
\hline
\end{tabular}

VAS: Visual Analogue Scale

Table 3: Assessment of urinary function, bowel function and sexual function 


\begin{tabular}{|c|c|c|c|c|c|c|c|}
\hline \multicolumn{2}{|c|}{ Variables } & \multirow{2}{*}{$\begin{array}{l}\text { Pre-operation } \\
\text { Median(IQR) } \\
4(3 \sim 5)\end{array}$} & \multirow{2}{*}{$\begin{array}{l}1 \text { month } \\
\text { Median(IQR) } \\
7(6 \sim 9)\end{array}$} & \multirow{2}{*}{$\begin{array}{l}3 \text { month } \\
\text { Median(IQR) } \\
5(5 \sim 8)\end{array}$} & \multirow{2}{*}{$\begin{array}{l}6 \text { month } \\
\text { Median(IQR) } \\
5(4 \sim 6)\end{array}$} & \multirow{2}{*}{$\begin{array}{l}12 \text { month } \\
\text { Median(IQR) } \\
4(3 \sim 5)\end{array}$} & \multirow{2}{*}{$\begin{array}{l}24 \text { month } \\
\text { Median(IQR) } \\
4(3 \sim 5)\end{array}$} \\
\hline $\begin{array}{l}\text { IPSS } \\
\text { Score }\end{array}$ & $\begin{array}{l}\text { RAS } \\
(n=169)\end{array}$ & & & & & & \\
\hline & $\begin{array}{l}\text { LAS } \\
(n=404)\end{array}$ & $4(3 \sim 6)$ & 7(7 9.75) & $7(6 \sim 8)$ & $6(4 \sim 7)$ & $4(3 \sim 6)$ & $4(3 \sim 6)$ \\
\hline & $P$ valve & 0.088 & 0.067 & {$[0.001$} & $\square 0.001$ & 0.186 & 0.185 \\
\hline \multirow[t]{3}{*}{$\begin{array}{l}\text { Wexner } \\
\text { Score }\end{array}$} & $\begin{array}{l}\text { RAS } \\
(n=169)\end{array}$ & $0(0,0)$ & & & $0(0,1)$ & $0(0,1)$ & $0(0,0)$ \\
\hline & $\begin{array}{l}\text { LAS } \\
(n=404)\end{array}$ & $0(0,0)$ & & & $1(1,3)$ & $1(0,1)$ & $0(0,0)$ \\
\hline & $\mathrm{P}$ valve & 0.885 & & & $\square 0.001$ & 00.001 & 0.787 \\
\hline \multirow[t]{3}{*}{$\begin{array}{l}\text { IIEF } \\
\text { Score }\end{array}$} & $\begin{array}{l}\text { RAS } \\
(n=46)\end{array}$ & $59.4 \pm 4.5$ & & $20.2 \pm 4.2$ & $38.5 \pm 4.5$ & $46.4 \pm 5.9$ & $51.4 \pm 6.2$ \\
\hline & $\begin{array}{l}\text { LAS } \\
(n=75)\end{array}$ & $59.1 \pm 4.9$ & & $19.1 \pm 4.1$ & $34.5 \pm 5.8$ & $41.0 \pm 5.6$ & $50.5 \pm 5.8$ \\
\hline & P valve & 0.707 & & 0.199 & $\square 0.001$ & 00.001 & 0.406 \\
\hline \multirow[t]{3}{*}{$\begin{array}{l}\text { FIFS } \\
\text { Score }\end{array}$} & $\begin{array}{l}\text { RAS } \\
(n=20)\end{array}$ & $25.1 \pm 3.9$ & & $16.6 \pm 3.7$ & $19.4 \pm 3.9$ & $21.3 \pm 4.2$ & $23.0 \pm 4.3$ \\
\hline & $\begin{array}{l}\text { LAS } \\
(n=55)\end{array}$ & $24.5 \pm 3.1$ & & $14.2 \pm 2.5$ & $16.1 \pm 2.7$ & $19.0 \pm 3.1$ & $22.1 \pm 3.7$ \\
\hline & $P$ valve & 0.484 & & 0.003 & $\square 0.001$ & {$[0.001$} & 0.389 \\
\hline
\end{tabular}

IPSS: International Prostate Symptom Score;IIEF: the International Index of Erectile Function. FIFS: the Female Sexual Function Index.

Table 4: Cox regression analyses of OS and DFS 


\begin{tabular}{|c|c|c|c|c|c|c|c|c|}
\hline \multicolumn{9}{|c|}{ Univariate and multivariate Cox regression analysis of predictors of OS and DFS } \\
\hline \multirow[t]{3}{*}{ Variables } & \multicolumn{4}{|c|}{ Overall survival } & \multicolumn{4}{|c|}{ Disease-free survival } \\
\hline & \multicolumn{2}{|c|}{ Univariate analysis } & \multicolumn{2}{|c|}{$\begin{array}{l}\text { Multivariate } \\
\text { analysis }\end{array}$} & \multicolumn{2}{|c|}{ Univariate analysis } & \multicolumn{2}{|c|}{$\begin{array}{l}\text { Multivariate } \\
\text { analysis }\end{array}$} \\
\hline & $\begin{array}{l}\mathrm{HR}(95 \% \\
\mathrm{Cl})\end{array}$ & $P$ & $\begin{array}{l}\mathrm{HR}(95 \% \\
\mathrm{Cl})\end{array}$ & $P$ & $\begin{array}{l}\mathrm{HR}(95 \% \\
\mathrm{Cl})\end{array}$ & $\mathrm{P}$ & $\begin{array}{l}\mathrm{HR} \\
(95 \% \\
\mathrm{Cl})\end{array}$ & $\mathrm{P}$ \\
\hline $\begin{array}{l}\text { Surgical approach: robotic } \\
\text { surgery vs laparoscopic } \\
\text { surgery }\end{array}$ & $\begin{array}{l}1.016 \\
(0.654- \\
1.579)\end{array}$ & 0.943 & NA & NA & $\begin{array}{l}0.979 \\
(0.668- \\
1.434)\end{array}$ & 0.914 & NA & NA \\
\hline Age $\geq 70$ years & $\begin{array}{l}1.477 \\
(0.932- \\
2.340)\end{array}$ & 0.097 & $\begin{array}{l}1.592 \\
(1.028- \\
2.648)\end{array}$ & 0.037 & $\begin{array}{l}0.382 \\
(0.911- \\
2.098)\end{array}$ & 0.128 & NA & NA \\
\hline Gender: male vs female & $\begin{array}{l}1.117 \\
(0.749- \\
1.667)\end{array}$ & 0.587 & NA & NA & $\begin{array}{l}1.252 \\
(0.881- \\
1.778)\end{array}$ & 0.21 & $\begin{array}{l}1.548 \\
(1.001- \\
2.023)\end{array}$ & 0.05 \\
\hline $\begin{array}{l}\text { Neoadjuvant } \\
\text { chemoradiotherapy }\end{array}$ & $\begin{array}{l}1.133 \\
(0.672- \\
1.908)\end{array}$ & 0.639 & NA & NA & $\begin{array}{l}1.475 \\
(0.945- \\
2.303)\end{array}$ & 0.087 & NA & NA \\
\hline Anastomotic leakage & $\begin{array}{l}1.717 \\
(0.801- \\
3.680)\end{array}$ & 0.165 & NA & NA & $\begin{array}{l}1.557 \\
(0.738- \\
3.283)\end{array}$ & 0.245 & NA & NA \\
\hline $\mathrm{R} 1$ resection & $\begin{array}{l}3.594 \\
(0.689- \\
18.759)\end{array}$ & 0.129 & NA & NA & $\begin{array}{l}3.197 \\
(0.686- \\
14.899)\end{array}$ & 0.139 & NA & NA \\
\hline Positive CRM & $\begin{array}{l}8.292 \\
(1.938- \\
35.490)\end{array}$ & 0.004 & $\begin{array}{l}14.637 \\
(4.547- \\
47.123)\end{array}$ & {$[0.0001$} & $\begin{array}{l}6.274 \\
(1.641- \\
23.994)\end{array}$ & 0.007 & $\begin{array}{l}10.416 \\
(3.261- \\
33.266)\end{array}$ & {$[0.0001$} \\
\hline T stage: $\mathrm{pT} 1-3$ vs $\mathrm{pT} 4 \mathrm{a}$ & $\begin{array}{l}2.111 \\
(1.425- \\
3.128)\end{array}$ & {$[0.0001$} & $\begin{array}{l}1.884 \\
(1.327- \\
2.674)\end{array}$ & 0.001 & $\begin{array}{l}1.574 \\
(1.131- \\
2.191)\end{array}$ & 0.007 & $\begin{array}{l}1.515 \\
(1.136- \\
2.019)\end{array}$ & 0.005 \\
\hline $\mathrm{N}$ stage: $\mathrm{pN} 0$ vs pN+ & $\begin{array}{l}1.521 \\
(1.357- \\
1.705)\end{array}$ & {$[0.0001$} & $\begin{array}{l}1.534 \\
(1.387- \\
1.697)\end{array}$ & {$[0.0001$} & $\begin{array}{l}1.382 \\
(1.251- \\
1.527)\end{array}$ & {$[0.0001$} & $\begin{array}{l}1.411 \\
(1.287- \\
1.548)\end{array}$ & {$[0.0001$} \\
\hline $\begin{array}{l}\text { Postoperative adjuvant } \\
\text { chemotherapy }\end{array}$ & $\begin{array}{l}1.877 \\
(0.878- \\
4.015)\end{array}$ & 0.104 & NA & NA & $\begin{array}{l}1.203 \\
(0.610- \\
2.372)\end{array}$ & 0.593 & NA & NA \\
\hline $\begin{array}{l}\text { Postoperative adjuvant } \\
\text { radiotherapy }\end{array}$ & $\begin{array}{l}0.843 \\
(0.546- \\
1.300)\end{array}$ & 0.439 & NA & NA & $\begin{array}{l}0.751 \\
(0.514- \\
1.098)\end{array}$ & 0.139 & NA & NA \\
\hline
\end{tabular}

HR: Hazards Ratio Cl: Confident interval; HR囚1 is positive predictors in survival otherwise negative predictors

Figures 


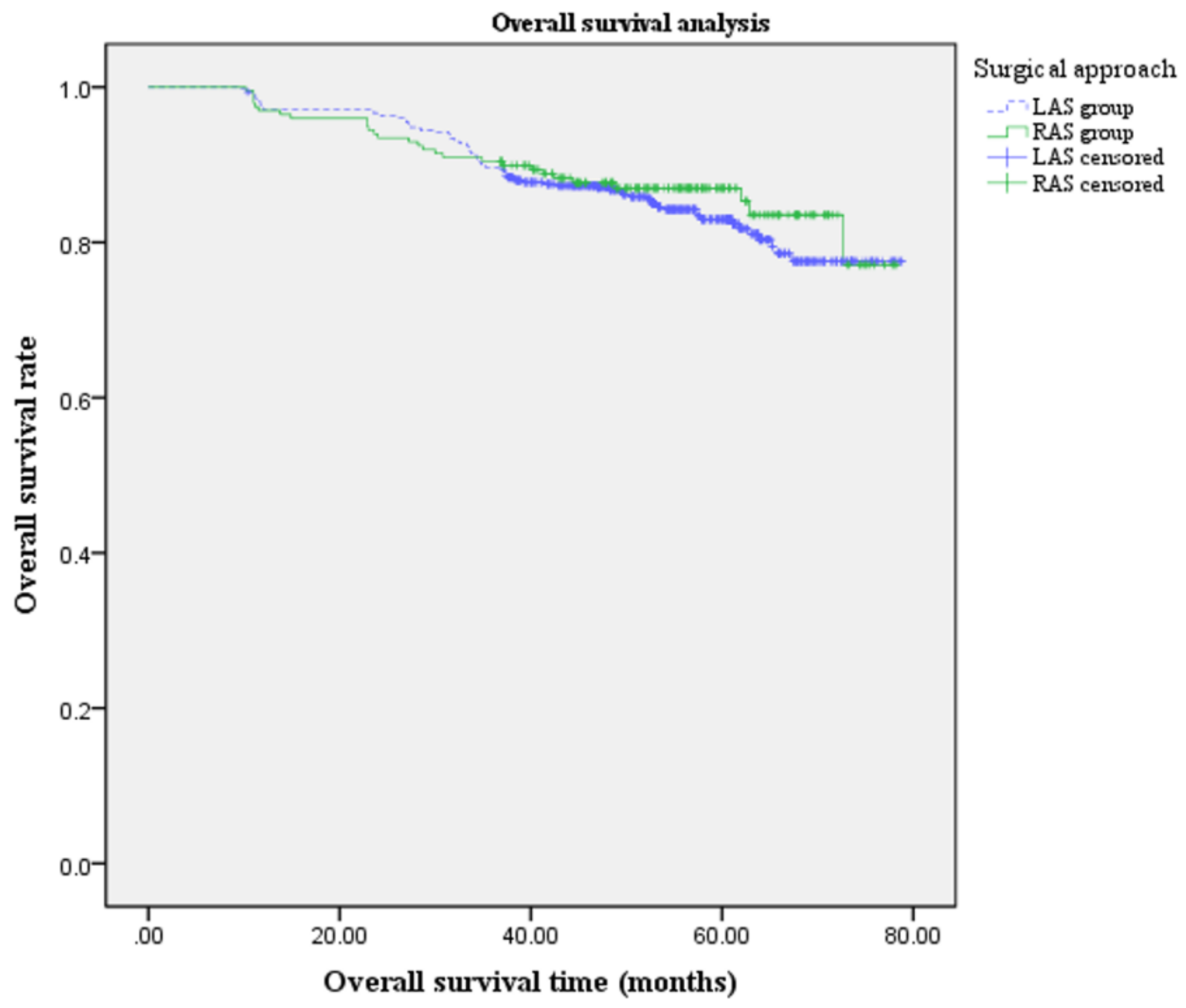

Figure 1

The 1,3 and 5 years of overall survival rate were $97 \%, 90.5 \%$ and $86.9 \%$ in the RAS group and $97.1 \%, 89.7 \%$ and $85.1 \%$ in the LAS group respectively $(\mathrm{P}=0.467)$. 




Figure 2

The 1, 3 and 5 years of disease-free survival rate were $94.0 \%, 86.4 \%$ and $80.3 \%$ in the RAS group and $94.4 \%, 84.7 \%$ and $79.2 \%$ in the LAS group respectively $(P=0.746)$.

\section{Supplementary Files}

This is a list of supplementary files associated with this preprint. Click to download.

- Data.xlsx

- IIEFFIFS.xIsx

- WexnerandIPSS.xIsx 